\title{
Bannayan-Riley-Ruvalcaba Syndrome in a Case Evaluated Due to Multinodular Goiter
}

\author{
(1) Özlem Korkmaz1, (1) Samim Özen1, (1) Hüseyin Onay2, (1) Ahmet Çelik33, (1) Yeşim Ertan4, \\ (1) Damla Gökşen1, (1) Şükran Darcan1
}

'Ege University Faculty of Medicine, Department of Pediatric Endocrinology, İzmir, Turkey

${ }^{2}$ Ege University Faculty of Medicine, Department of Genetics, Izmir, Turkey

${ }^{3}$ Ege University Faculty of Medicine, Department of Pediatric Surgery, İzmir, Turkey

${ }^{4}$ Ege University Faculty of Medicine, Department of Pathology, İzmir, Turkey

\begin{abstract}
Bannayan-Riley-Ruvalcaba syndrome (BRRS) is characterized by macrocephaly, pigmented macules on the glans penis and benign mesodermal hamartomas. 9.6-year-old boy was referred to the pediatric surgeon following an observation of a subcutaneous lipomatous lesion and numerous nodules in the thyroid gland via ultrasonography performed due to swelling in the neck first noticed approximately 3 months previously. Thyroid ultrasonography revealed numerous nodules with distinct margins in both lobes of the thyroid gland, some exhibiting calcification and others hypoechoic areas, and a total thyroidectomy was performed due to a suspicion of malignity. After surgery, the patient was referred to the Pediatric Endocrinology Department. On physical examination, his weight was $30 \mathrm{~kg}$ [standard deviation score (SDS): - 0.38 ], height $140 \mathrm{~cm}$ (SDS: 0.71 ) and head circumference $59.5 \mathrm{~cm}$ (SDS: +3.21). Pubic hair was Tanner stage 2, bilateral testes $3+3 \mathrm{~mL}$ palpable. There was multiple hyperpigmented lesions on the penile skin. His past medical history revealed that pubic hair development was reported at the age of 8 years. Laboratory examinations revealed a 17-OH progesterone level of $4.8 \mathrm{ng} / \mathrm{mL}$, bone age compatible with 8 years. P. V281L heterozygous mutation was determined via CYP21A2 mutation screening performed for non-classic congenital adrenal hyperplasia. BRRS was primarily suspected in this case of macrocephaly, lipomatous lesions and pigmented macular lesions on the penis. Heterozygous p.C136R mutation was determined via PTEN mutation scanning.

Keywords: Bannayan-Riley-Ruvalcaba syndrome, thyroidnodule, macrocephaly
\end{abstract}

\section{Introduction}

Mutation of the PTEN tumor suppression gene leads to PTEN hamartoma tumor syndrome (PHTS). PHTS includes Cowden syndrome, Bannayan-Riley-Ruvalcaba syndrome (BRRS) and Proteus-like syndrome (1,2). BRRS is the pediatric form of PHTS and is characterized by macrocephaly, pigmented macules on the glans penis and benign mesodermal hamartomas (primary subcutaneous and visceral lipomas, multiple hemangiomas and intestinal polyp). These cases may be accompanied by dysmorphic findings, joint hyperelasticity, pectus excavatum, scoliosis, café-au lait spots, frontal bossing, hypertelorism, a short palpebral fissure, a long philtrum and proximal muscle myopathy (3). Growth and mental retardation may be seen in half of these cases. Intestinal polyposis may be seen in $35-40 \%$ of cases, and clinical findings of anemia, diarrhea and small intestinal invagination may also be observed (3-5). 
In addition, 30\% of cases of BRRS have been shown to be at risk of multinodular goiter, thyroid adenoma, differentiated non-medullary thyroid cancer or Hashimoto's thyroiditis (6).

\section{Case Report}

9.6-year-old boy was referred to the Pediatric Surgery Department following an observation of a subcutaneous lipomatous lesion and multiple nodules in the thyroid gland via ultrasonography performed due to swelling in the neck first noticed approximately 3 months previously. Detailed thyroid ultrasonography revealed multiple nodules with distinct margins in both lobes of the thyroid gland, some exhibiting calcification and others hypoechoic areas. Following a total thyroidectomy performed due to a suspicion of malignity, the case was referred to the Pediatric Endocrinology Department. On physical examination, the patient's weight was $30 \mathrm{~kg}$ [standard deviation score (SDS): -0.38], height $140 \mathrm{~cm}$ (SDS: 0.71 ) and head circumference $59.5 \mathrm{~cm}$ (SDS: +3.21). Axillary hair was not present, pubic hair was Tanner stage-2, testes were $3 \mathrm{~mL}$ in size and hyperpigmented lesions on the penile skin were observed (Figure 1). Family history revealed that the patient's maternal grandmother had been diagnosed with colon cancer at the age of 42. Laboratory examinations at the time of presentation revealed free thyroxine: 0.58 $\mathrm{ng} / \mathrm{dL}$ (0.89-1.76) and thyroid-stimulating hormone: 89.2 $\mathrm{mU} / \mathrm{L}$ (0.35-5.5). Full blood count, kidney and liver functions and ion levels were within normal limits. $2 \mathrm{mcg} / \mathrm{kg} / \mathrm{d}$ L-thyroxin for hypothyroidism was started. Investigations were performed for premature pubarche with the findings as follows; follicle stimulating hormone: $0.78 \mathrm{mIU} / \mathrm{mL}$ (0.26-3), luteinizing hormone: $0.2 \mathrm{mIU} / \mathrm{mL}(0.02-0.3)$ free testosterone: $1.4 \mathrm{pg} / \mathrm{mL}$ (0.4-0.9), total testosterone: $0.1 \mathrm{ng} /$ $\mathrm{dL}(<2.5-10)$, dehydroepiandrosterone sulfate: $93 \mathrm{mcg} / \mathrm{dL}$ (1383), $17-\mathrm{OH}$ progesterone: $4.8 \mathrm{ng} / \mathrm{mL}(<0.9)$ cortisol: $12 \mathrm{mcg} /$ $\mathrm{dL}$ (3-21), adrenocorticotropic hormone: $22 \mathrm{pg} / \mathrm{mL}$ (6-48) and bone age of 8 years. His 17-OH progesterone level was high, and a p.V281L heterozygous mutation was determined via CYP21A2 mutation scanning performed for non-classic congenital adrenal hyperplasia. Since the patient's bone

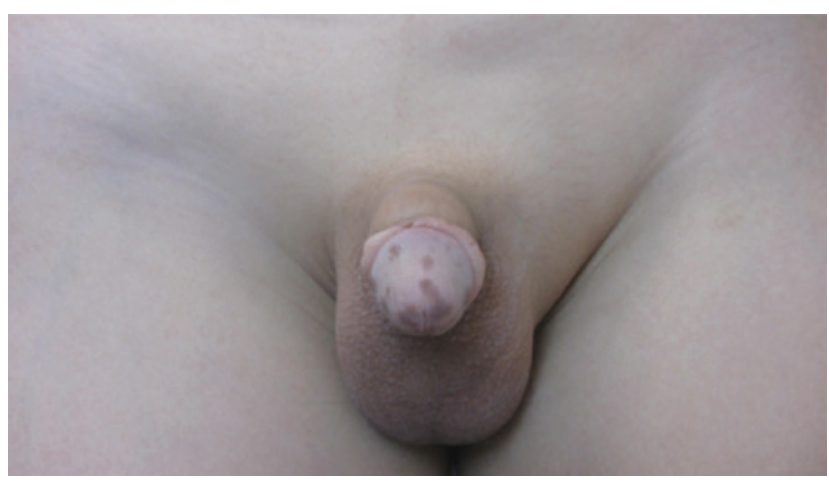

Figure 1. Hyperpigmented lesions on the penis age was not advanced, we decided to maintain monitoring without treatment. The post-thyroidectomy pathology report was compatible with follicular nodular disease. The case was assessed as BRRS based on the macrocephaly, lipomatous lesions and pigmented macular lesions on the penis. Polypoid structures were observed in the bulbus and throughout the colonic mucosa via endoscopy performed in light of gastrointestinal system lesions, and monitoring was recommended. Cranial magnetic resonance imaging (MRI) in this case with macrocephaly revealed bilateral hamartomatous lesions located in the bilateral cerebral hemisphere anterior periventricular deep white matter, and monitoring with annual cranial MRI was decided upon. Heterozygous p.C136R mutation was determined via PTEN mutation scanning (Figure 2). We report this case in which CYP21A2 mutation was determined incidentally together with PTEN gene mutation due to the coincidence of two different mutations and the rarity of the phenomenon. The inform consent was taken from the patients' parents for publication.

\section{Discussion}

PHTS is an autosomal dominant inherited disease resulting from a germline mutation in the PTEN gene. BRRS, the pediatric form of PHTS, was first described in 1971 (7). BRRS is characterized by macrocephaly, pigmented macules on the glans penis and benign mesodermal hamartomas (4). No diagnostic criteria for BRRS has been described. Marsh et al. (1) proposed the presence of at least 3 of macrocephaly, lipomatosis, hemangiomas and pigmented macules on the glans penis as diagnostic, while Parisi et al. (8) considered the presence of 2 out of 3 findings described as macrocephaly, hamartomas (lipoma, hemangioma or intestinal polyp) as diagnostic.

Our case was first referred to our clinic by the Pediatric Surgery Department following a total thyroidectomy performed following determination of multinodular goiter, thyroid nodules containing calcification and a hypoechoic area via ultrasonography. The risk of cancer associated with BRRS is still unclear (9). However, differentiated thyroid cancers are thought to derive from follicular adenomas.

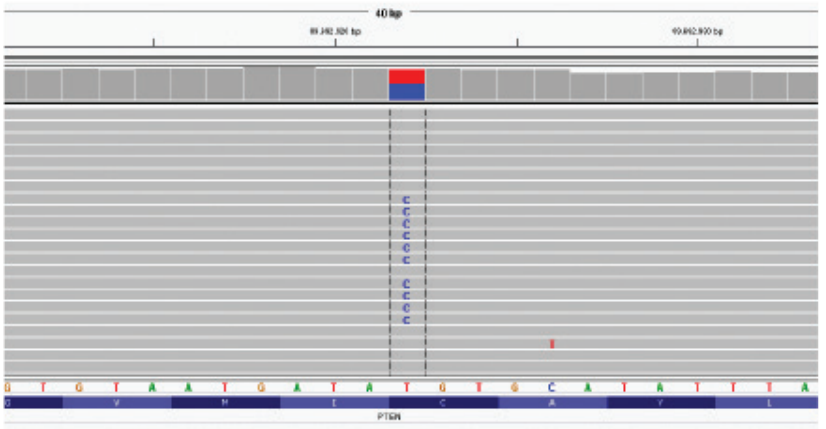

Figure 2. PTEN p.C136R (c.406TC) 
Prophylactic surgery is preferred in these cases since oxyphilic and follicular cytology cannot clearly differentiate between benign and malign nodules (10-12). However, prophylactic thyroidectomy is not recommended in cases of BRRS without thyroid nodule. Multiple adenomatoid thyroid disease and lymphocytic thyroiditis are frequently seen in cases of BRRS (13). Total thyroidectomy was performed in our case due to suspected malignant nodule via thyroid ultrasonography. The postoperative pathology report was compatible with follicular adenoma.

Several subcutaneous lesions, the largest of which was $2 \times 1.5 \mathrm{~cm}$ in size and suggestive of lipoma were observed on the neck and thoracic anterior wall via superficial tissue ultrasonography of the cutaneous lesions. Following dermatological consultation regarding the lesions on the penis determined, under the physical examination, that these were benign penile lentiginous lesions, and annual monitoring of these together with the lipomatous lesions on the body was advised.

Intestinal hamartomatous polyp development has been reported in $35-40 \%$ of cases of BRRS (14). A polypoid appearance was also observed along the esophagus, bulbus and the entire colon in our case, and the asymptomatic patient was referred to the Pediatric Gastroenterology Department for observation. It was suggested that the polyps in these cases may be associated with invagination and rectal bleeding, but no evidence has been obtained to show that this increases the risk of colorectal cancer. No fecal occult blood, investigated for screening purposes, was determined in our case.

The cancer screening protocol in patients with BRRS is not explicitly described, although 6 monthly complete blood count, urine tests and thyroid and abdominal ultrasonography are recommended. Monitoring with fecal occult blood investigation and periodic MRI for the risk of intracranial tumor are recommended in cases in which intestinal polyp is determined (15). Hamartomatous lesions in bilateral hemisphere anterior periventricular deep white matter and left parietal deep white matter were observed via cranial MRI in our case. The Oncology and Brain Surgery departments were consulted and monitoring with annual MRI was advised. Neurodevelopmental development with a total IQ 99 score from the WISC-R test administered by a psychologist was evaluated as within normal limits.

BRRS is inherited in an autosomal dominant manner, but a new mutation is determined in $37 \%$ of cases. PTEN gene mutation positivity has been determined in 50-60\% of cases with a clinical diagnosis of BRRS (1). PTEN is a tumor suppressor gene located on the long arm of the $10^{\text {th }}$ chromosome. After getting informed consent from the parents, DNA was extracted from peripheral leucocytes using standard methods. Heterozygous p.C136R (TGT>CGT) PTEN gene mutation, which was previously identified, was also positive in our case. Mutation screening was also performed for the parents and sibling due to autosomal dominant inheritance, but no mutation was determined. Despite a history of colon cancer at the age of 42 in the maternal grandmother, genetic analyses could not be performed since she was no longer alive. PTEN mutation-positive find a genotype/phenotype correlation among 42 patients from 26 families with PTEN mutations and clinical features of BRRC.

In conclusion, other accompanying pathologies can be determined with careful systemic physical examination in patients in whom thyroid nodule is determined. Cases in which BRRS, one of the PHTS, is suspected should be monitored with a multidisciplinary approach including pediatricians, pediatric endocrinologists, gastroenterologists, neurologists, oncologists, dermatologists and pediatric surgeons.

\section{Ethics}

Informed Consent: The inform consent was taken from the patients' parents for publication.

Peer-review: Externally and internally peer-reviewed.

\section{Authorship Contributions}

Surgical and Medical Practices: Ö.K., S.Ö., A.Ç., Concept: Ö.K., S.Ö., Ş.D., D.G., Design: Ö.K., S.Ö., Ş.D., D.G., Data Collection or Processing: Ö.K., H.O., A.Ç., Y.E., Analysis or Interpretation: Ö.K., S.Ö., H.O., Y.E., Ş.D., Literature Search: Ö.K., S.Ö., Writing: Ö.K., S.Ö.

Conflict of Interest: No conflict of interest was declared by the authors.

Financial Disclosure: The authors declared that this study received no financial support.

\section{References}

1. Marsh DJ, Kum JB, Lunetta KL, et al. PTEN mutation spectrum and genotype-phenotype correlations in Bannayane-Riley Ruvalcaba syndrome suggest a single entity with Cowden syndrome. Hum Mol Genet 1999;8:1461-72.

2. Eng C. Will the real Cowden syndrome please stand up: revised diagnostic criteria. J Med Genet 2000;37:828-30.

3. Hendriks YM, Verhallen IT, van der Smagt IJ, et al. BannayanRiley-Ruvalcaba syndrome: further delineation of the phenotype and management of PTEN mutation-positive cases. Fam Cancer 2003;2:79-85.

4. Haggitt RC, Reid BJ. Hereditary gastrointestinal polyposis syndromes. Am / Surg Pathol 1986;10:871-7.

5. Harned RK, Buck LL, Sobin LH. The hamartomatous polyposis syndromes: clinical and radiologic features. AJR Am I Roentgenol 1995;164:565-71.

6. Blumenthal GM, Dennis PA. PTEN Hamartoma tumor syndromes. Eur J Hum Genet 2008;16:1289-1300.

7. Bannayan GA. Lipomatosis, angiomatosis, and macrencephalia. A previously undescribed congenital syndrome. Arch Pathol 1971;92:1-5. 
8. Parisi MA, Dinulos MB, Leppig KA, Sybert VP, Eng C, Hudgins $L$. The spectrum and evolution of phenotypic findings in PTEN mutation positive cases of Bannayane Rileye Ruvalcaba syndrome. I Med Genet 2001;38:52-8.

9. Ngeow J, Mester J, Rybicki LA, Ni Y, Milas M, Eng C. Incidence and clinical characteristics of thyroid cancer in prospective series of individuals with Cowden and Cowden-Like syndrome echaracterized by germline PTEN, SDH, or KLLN alterations. Article J Clin Endocrinol Metab 2011;96:2063-71.

10. Corrias A, Mussa A. Thyroid Nodules in Pediatrics: Which ones can be left alone, which ones must be investigated, when and how. J ClinRes Pediatr Endocrinol 2013;5:57-69.

11. Corrias A, Mussa A, Baronio F, et al. Diagnostic features of thyroid nodules in pediatrics. Arch Pediatr Adolesc Med 2010;164:714-9.
12. Corrias A, Cassio A, Weber G, et al. Thyroid nodules and cancer in children and adolescents affected by autoimmune thyroiditis. Arch Pediatr Adolesc Med 2008;162:526-31.

13. Smith JR, Marqusee E, Webb S, et al. Thyroid nodules and cancer in children with PTEN hamartoma tumor syndrome. ) Clin Endocrinol Metab 2011;96:34-7.

14. Haggitt RC, Reid BJ. Hereditary gastrointestinal polyposis syndromes. Am J Surg Pathol 1986;10:871-87.

15. Peiretti V, Mussa A, Feyles F, et al. Thyroid Involvement in Two Patients with Bannayan-Riley-Ruvalcaba Syndrome. I Clin Res Pediatr Endocrinol 2013;5:261-5. 